\title{
An Interesting "Fort"
}

\section{Author(s): Capt. A. Gorham}

Source: Kerry Archaeological Magazine, Vol. 3, No. 13 (Oct., 1914), pp. 12-19

Stable URL: http://www.jstor.org/stable/30022074

\section{Accessed: 13-05-2016 10:34 UTC}

Your use of the JSTOR archive indicates your acceptance of the Terms \& Conditions of Use, available at

http://about.jstor.org/terms

JSTOR is a not-for-profit service that helps scholars, researchers, and students discover, use, and build upon a wide range of content in a trusted digital archive. We use information technology and tools to increase productivity and facilitate new forms of scholarship. For more information about JSTOR, please contact support@jstor.org. 

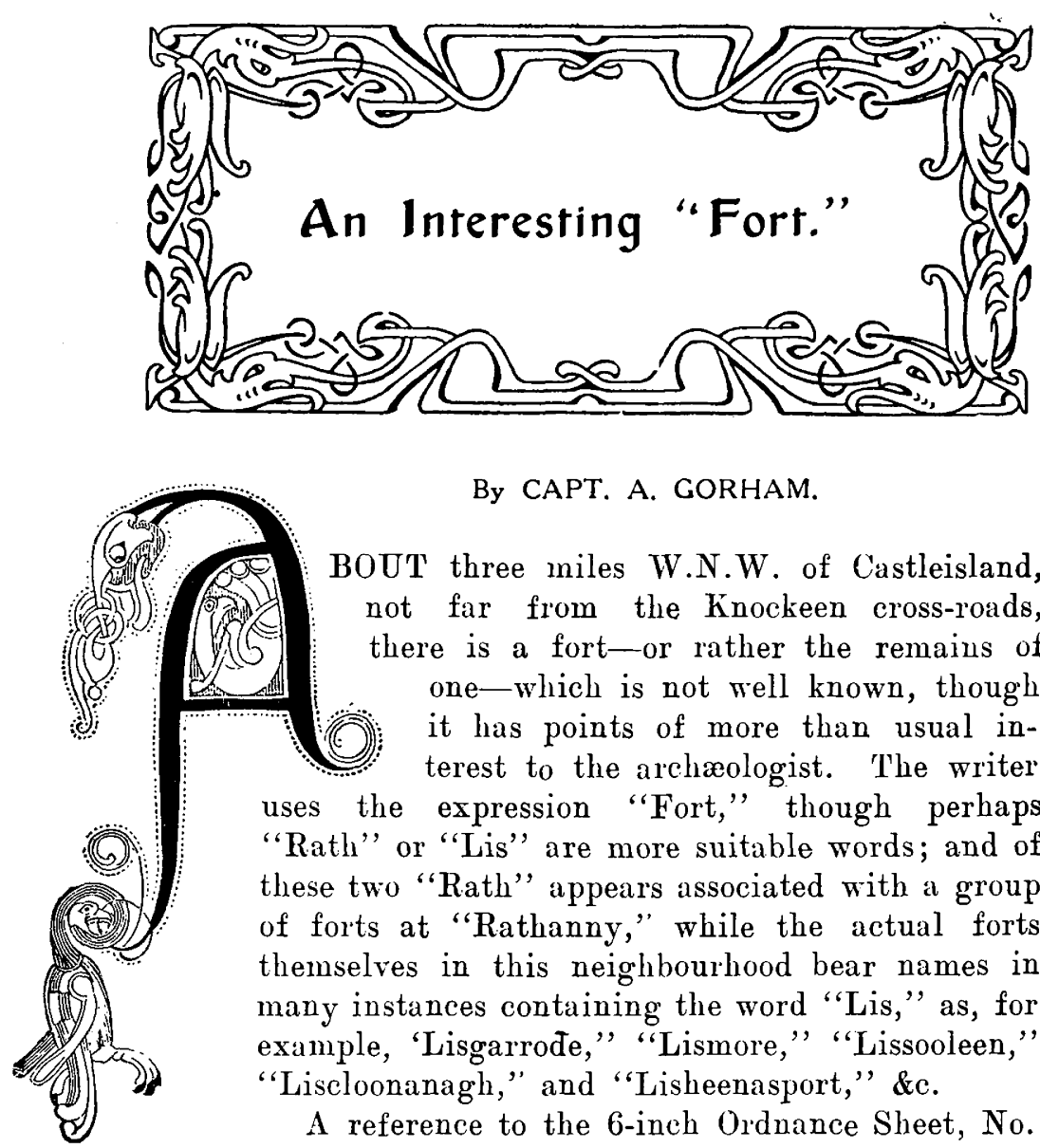

By CAPT. A. GORHAM.

BOUT three miles W.N.W. of Castleisland, not far from the Knockeen cross-roads, there is a fort-or rather the remains of one-which is not well known, though it has points of more than usual interest to the archæologist. The writer uses the expression "Fort," though perhaps "Rath" or "Lis" are more suitable words; and of these two "Rath" appears associated with a group of forts at "Rathanny," while the actual forts themselves in this neighbourhood bear names in many instances containing the word "Lis," as, for example, 'Lisgarrode," “Lismore," "Lissooleen," "Liscloonanagh," and "Lisheenasport," \&c.

A reference to the 6-inch Ordnance Sheet, No. 39, Kerry, and to the Sketch Map, Fig. 1, will indicate the exact locality of the fort about to be described, and it will be observed that of the forts marked A B C D and E on Sketch Map, Fig. 1, those marked A and D are not shown on the Ordnance Map.

The fort we are at present concerned with is the one marked $\mathrm{D}$, which the writer has investigated from time to time during the past year, by the kind permission of $G$. Hickson, Esq., of Woodville.

That this particular fort should have escaped notice of the Ordnance surveyors, in spite of its proximity to the 


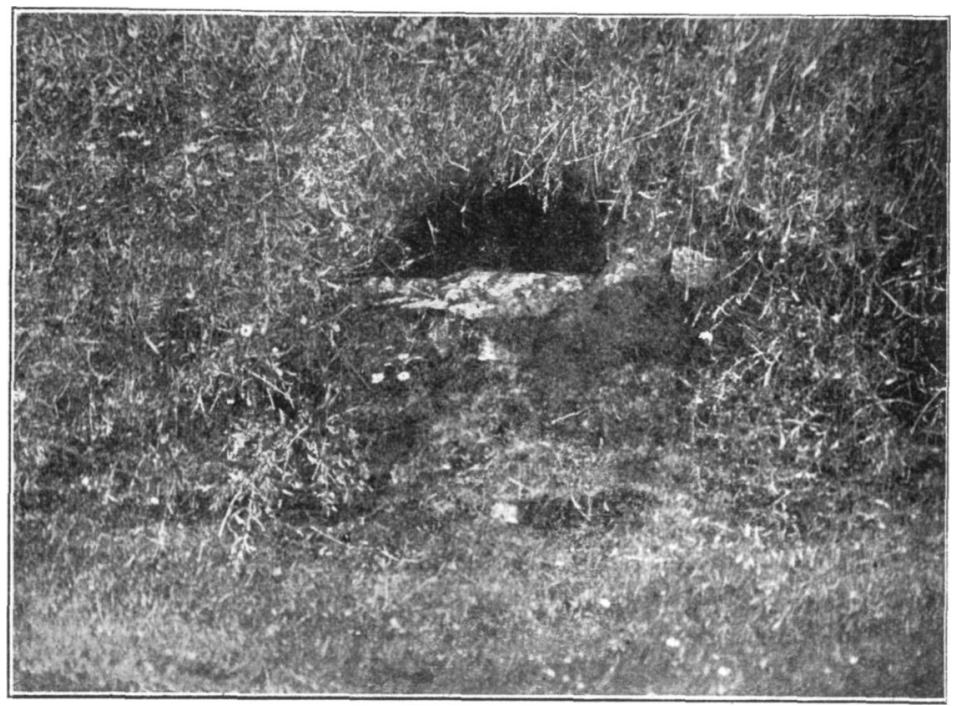

ENTRANCE TO CHAMBERS (K).

road, is doubtless due to the fact that there is very little left of the original parapet, and practically nothing of the surrounding trench; but on arrival at the spot indicated the remains may be easily seen, as also a hole (a little to the north of the centre of the fort) which forms the present entrance (K). (See Figs. $z$ and 3 and photograph.)

On entering this hole we find the ground sloping down rapidly to the west, while to the north-east is a blind chamber some 6 feet long and 2 feet 3 broad and 2 feet 6 high, which I have called a "guard chamber," Fig. 2.

Dropping down to the west we come to a square trapdoor, 2 feet $\times 2$ feet. To form this the lime stone bed rock has been cut down on the east, the remainder built round. (See section on A B, Fig. 3.) Passing through this trapdoor, we drop down about five feet, and find two holes leading north and south, respectively, of which the northern one is seen in section on A B.

Passing through this hole, which is $2 \mathrm{ft.} 9 \mathrm{in.}$ long, $2 \mathrm{ft} .7$ in. high, and $1 \mathrm{ft.} 9 \mathrm{in}$. broad, we enter a very perfect "bee-hive" chamber, 8 feet long, $6 \mathrm{ft}$. 6 in. broad, and 


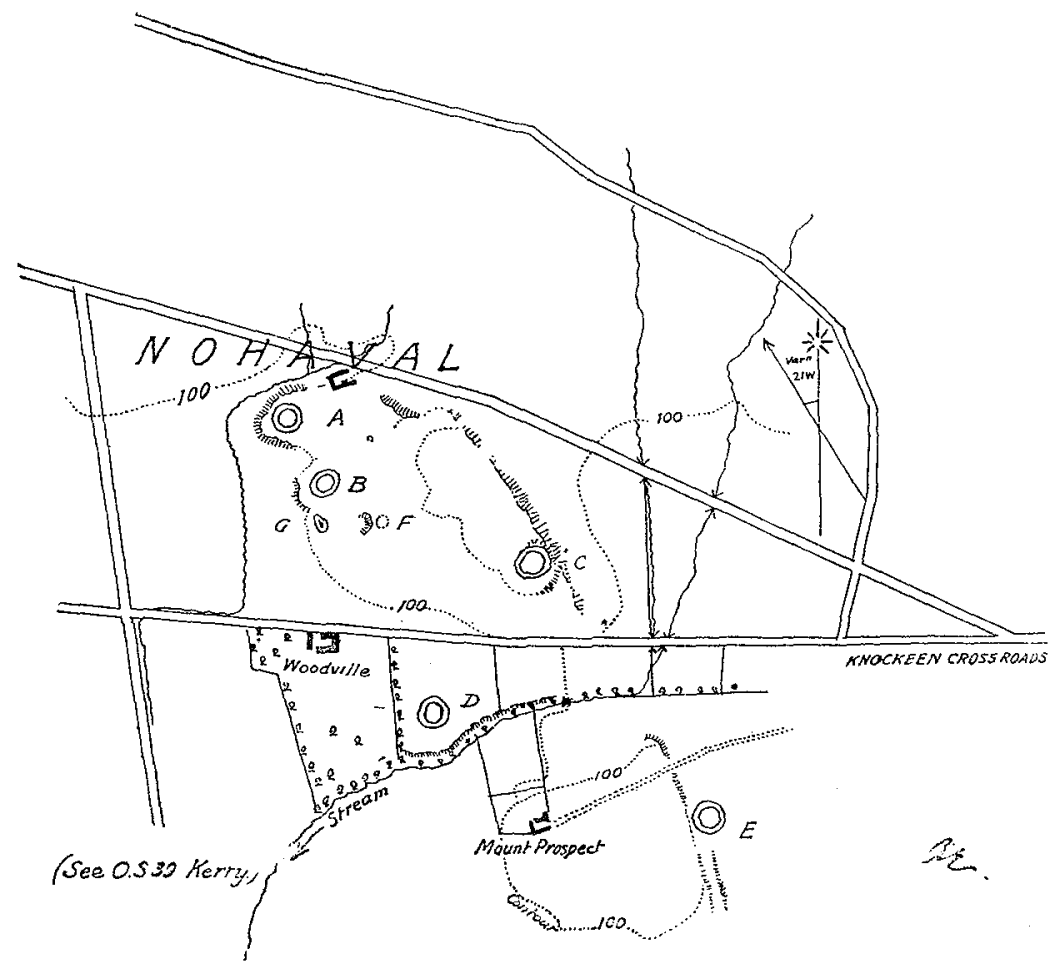

Fig. 1

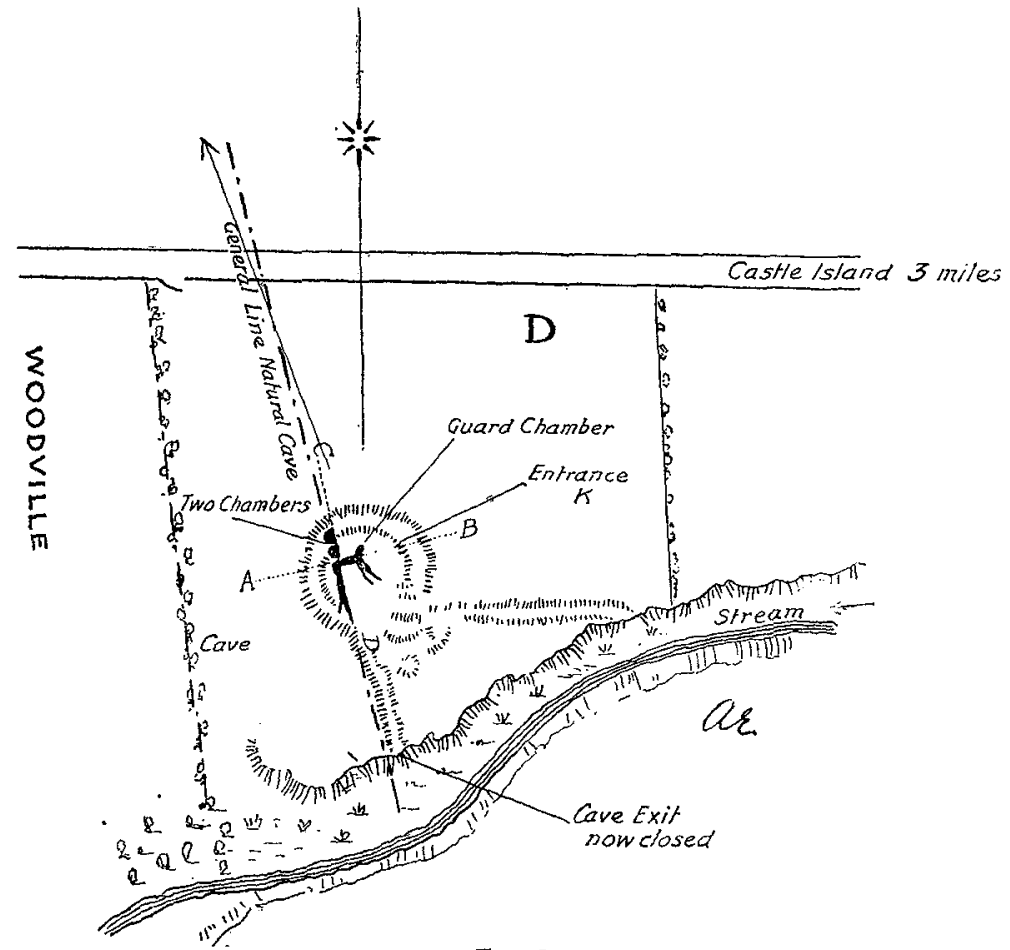

Fig. 2. 

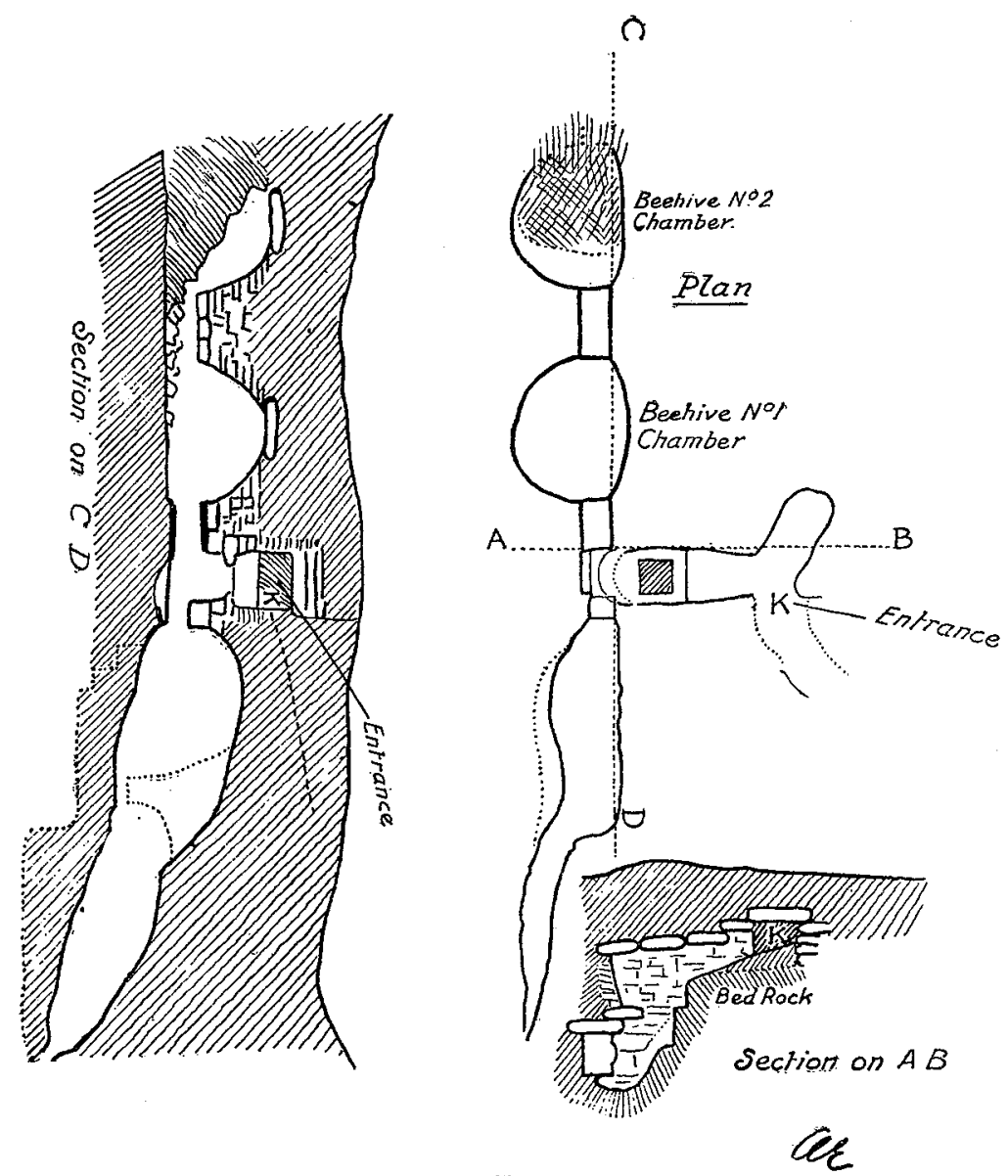

Fig. 3. 
$5 \mathrm{ft} .7$ in. high in centre, measuring from present floor level, which appears to be very much what it was originally.

On the northern side of this bee-hive (No. 1) another small passage, exactly opposite to the former, leads to a second beehive chamber, but here further progress is blocked, as the northern wall of this chamber has fallen in. (See plan and section on C D, Fig. 3.)

Returning to the trap-door, we find the southern passage leads sharply down a slope formed of a mass of loose stunes and some earth, and find ourselves in a naturai cave, which may be followed to a point some 24 feet further on, the floor of which slopes down to the west and drops towards the south. (See Fig. 3.)

The mass of rubble and stones on floor of this cave, as also traces of building on sides near entrance, indicate that a large chamber was built in here, which has since collapsed, and the dotted line in Fig. 3, section C D, shows what was probably the nature of this chamber.

Glancing over what we have done up to the present, we see that very skilful use has been made of a natural cave to make the required underground chambers for this fort, and the conclusion is irresistibly forced upon us that the situation and dimensions and nearness to the surface, \&c., of the natural cave have in this instance, at least, determined the position and locality of the whole fort. But there is a point possibly more important than any of these, and that is the water supply. But now let us return to the surface, as it is getting rather "stuffy" down below!

If we now consult Fig. 2 we shall see that the general line of this cave runs for some 50 yards from the fort southwards, and cuts a steep bank quite close to the present stream. This bank is six to eight feet high, and was cut out of the solid limestone, no doubt by; the stream which originally washed up against it.

On the surface we find the ground banked up along this very line, and there can be no doubt that here we have the "covered way" to the water supply. An inhabitant, living about a mile from Woodville, has assured me that twenty years ago he saw daylight from the fort cave looking down 
towards the stream, and I think the reason I did not manage to is because the bank is now densely overgrown with bushes and brambles, \&c.; also in that time more of the cave roof may have fallen in. Regarding the matter from a geological point of view, and from my general observations of caves in this neighbourhood, I have no doubt that this cave or fissure in the limestone not only connects the fort with the streama mere 50 yards-but extends northwards for perhaps half a mile or more, which matter I will refer to later on.

Another bank runs from the fort due east, and without excavation it would be hard to say whether this indicates another subterranean passage or not; but I feel inclined to think it does.

On the south-east, between these two banks, the edge of the parapet is very much broken up, and in places the limestone is exposed, with indications of quarrying, while there are in addition several mounds, probably the ruins of stone-built structures.

It is noteworthy that there is a hollow in the ground from the entrance $(\mathbf{K})$ curving round towards the south-east, and it would be very interesting to clear this out and follow the masonry, as it is quite possible that this would lead to the discovery of other chambers. Then again it would be well worth the trouble to excavate down at the place corresponding to the northern side of the second bee-hive chamber, as here we should strike the cave again, and probably chambers beneath the parapet, or an exit into the old fort trench.

I may here mention that $I$ have been unable to find any traces of marks on the stones of this fort, as, for instance, ()gham inscriptions, but many of the roofing stones are very large, being 18 in. to 2 feet broad, 3 feet long and 8 in. thick. The entrance passages to the "bee-hive" chambers are remarkably well constructed of massive blocks, with very flat surfaces, and show the great care and labour with which this building work was carried out, perhaps 1,500 years ago, at a depth some 12 feet below the surface. Only one large slab has anything peculiar about it, and that is the roofing slab just over the trap-door, which has a circular hole cut 
through its centre. 'This hole may have been there before the stone was used as a roofing slab, but quite probably was made at the time of building, either to let in light, or very likely to pass a rope through for hoisting the trap-door.

It will now be as well to take a look round the country in the neighbourhood, and it will be seen that Fort $\mathrm{D}$ forms one of a group of forts, and as it so happens built on lower ground than any of them. (See Fig. 1.)

The streams coming from the north unite and pass west. ward between two small knolls, as shown by position of the 100-foot contour.

The knoll on which Fort $\mathrm{C}$ is placed is flanked on northeast by a steep scarp, which has been brought about naturally by a slight fault, and this may be traced on the other side of the valley running past Fort $\mathbf{E}$.

The stream on the west passes Fort $A$, and flows southward, and originally flowed past Woodville.

The small promontory at $A$ is scarped nearly vertically, but some of this is due to quarrying in recent times.

Near $F$ is a small but ancient quarry, where the limestone is horizontal, with nearly vertical fracture, and the formation is flaked or split up, naturally affording an ideal place for getting out large slabs, such as are used for roofing in the forts.

At $\mathrm{F}$ is a mound or tumulus, and as it is situated above the quarry, is very probably a burial place and not a mere heap of scraps from the quarry.

Just below $\mathrm{F}$ is a hollow, now filled with dense undergrowth, which is undoubtedly a "Poul," or cavity caused by fallen-in cave roof, and it will now be observed that this "Poul" lies in the line joining forts D, B and A, and is, moreover, in prolongation of the cave passing through Fort D, and I am of opinion that the stream north of Aor water from it-in bygone geological ages entered a fissure about $\mathbf{A}$, and in time wore out a cave from $\mathbf{A}$ and $\mathrm{D}$. That cave may or may not have been dry at the time the forts were built-probably not-and indeed the water probably percolates through it now at the lower levels.

One thing is very probable, namely, that forts A, B, 
and I were connected, at one time, by this cave, and this bears out local tradition, and also the theory that such is very frequently the case in Kerry. In some instances we are told that passages have been constructed from fort to fort, but the writer has come to the conclusion that, in addition to such passages, in Kerry, where the limestone is "honeycombed" with large and small caves and fissures and fractures, running generally north and south, the ancient beings who constructed the "Forts," whether they were Dannans or otherwise, used these natural caves to full advantage in most cases.

In conclusion, we may note that the name of the field in which Fort $D$ is situated is Koloo or Colloo, but beyond that this interesting spot has remained unnamed and hardly known to any but local inhabitants.

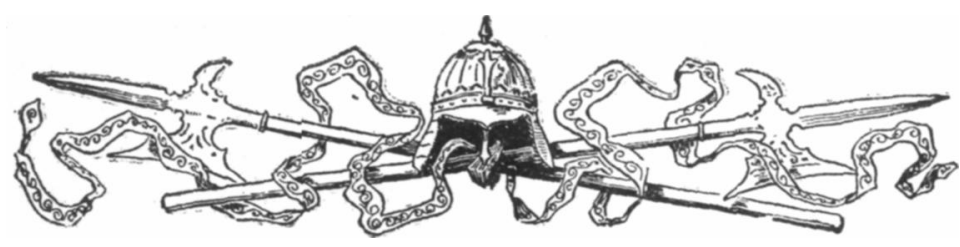

